\title{
COAGULATION TIME IN THE SELECTION OF CASES FOR ANTICOAGULANT TREATMENT
}

\author{
BY \\ A. A. FITZGERALD PEEL \\ From the Victoria Infirmary, Glasgow \\ Received June 12, 1952
}

Anticoagulant therapy in cardiac infarction has raised several new problems. Its efficacy in reducing both mortality and complications appears to be beyond doubt. Tulloch and Gilchrist (1950) summarized the results in eleven earlier series and added their own figures : anticoagulants reduced the mortality from 29 to 15 per cent. The incidence of thrombo-embolic complications rose from 11 per cent before 1940 to 28 per cent between 1945 and 1948 ; these occurred in 28 per cent of Tulloch and Gilchrist's control cases but in only 13 per cent of their treated group. On the other hand anticoagulant therapy has disadvantages. Tromexan and dicoumerol necessitate frequent laboratory tests and few patients can be treated at home, thereby increasing the demands on hospital accommodation. Heparin is expensive and requires frequent intravenous injections ; the efficacy of intramuscular injections has yet to be proved.

The mortality figures show that 15 per cent of patients with cardiac infarction will die and 71 per cent will recover whether anticoagulants are given or not ; in 14 per cent anticoagulants may save life. Similarly they prevent complications in 15 per cent of cases. A maximum figure of 29 per cent includes all these for whom anticoagulants are essential ; for the rest they are immaterial. The first problem is to differentiate those who require anticoagulants from those who do not.

A second problem concerns their use in cardiac ischæmia without infarction and in the "slight coronary attacks" of Papp and Shirley Smith $(1951, a$ and $b)$. These authors state that "anticoagulant treatment is not indicated since the risk of thrombo-embolic complications or extension of infarction is so slight," but continue : "Further thrombosis in major coronary branches must remain an ever existing danger." Cases that start as a " slight coronary attack" but later develop the picture of severe infarction are by no means rare, and in this group also, anticoagulants are sometimes essential but often unnecessary.

Finally Mounsey (1951) has re-emphasized the well-known prodromal symptoms that occur in some cases of cardiac infarction. Post-mortem evidence suggested different pathological processes as the cause of the prodromal symptoms. In one case they were attributed to incomplete occlusion of a vessel by a thrombus, in one to hæmorrhage into an atherosclerotic plaque, and in one to progressive atheromatous narrowing. These pathological findings suggest that anticoagulants are essential in some cases, dangerous in some, and immaterial in others. Papp and Smith $(1951, c)$ now advocate anticoagulants in this prodromal coronary syndrome.

The aim of this paper is to differentiate those patients in each of the foregoing groups who must, from those who need not, be given anticoagulants. As far as I am aware this has not been tried. A personal attempt to base the selection on clinical grounds made during 1950 met with complete lack of success. Selection for anticoagulant treatment might reasonably be based on tests of blood coagulability. Ogura et al. (1946), using Waugh and Ruddick's (1944) " heparin tolerance test," showed that acceleration of clotting occurred after a cardiac infarction in 78 per cent of their cases. It commonly appeared on the third day and lasted for three weeks, occasionally persisting for four or five weeks. The authors made the important observation that extension of the original 
infarct and thrombo-embolic complications only occurred at a time when acceleration was present ; they assume that once it has developed, the acceleration may lead to further complications.

The Waugh-Ruddick test involves a number of tubes with differing dilutions of blood and heparin ; it is essentially a laboratory test, ill adapted for use in a patient's home. Rosenthal (1949) introduced a modified and simplified test requiring only a single tube : the result remained reasonably constant with successive determinations in normal controls ; bed rest and digitalis each caused acceleration. Eight of his eleven cases with prolonged times had clinical evidence of hæmorrhage, and he implies that the reverse is equally likely to be true. This seemed a hopeful test for selection of cases for anticoagulant treatment. Since the beginning of 1951 it has been used in all cases of cardiac infarction, in " slight coronary attacks,". in patients with recent onset of coronary pain, and in those whose former coronary pain had changed in behaviour or intensity.

\section{The HeParin-Retarded Coagulation Time (HRCT)}

Rosenthal's (1949) technique has been modified in one important respect. He specifies rubber-stoppered glass test tubes of $13 \mathrm{~mm}$. bore and $7.5 \mathrm{~cm}$. length; we have used tutes of $7 \mathrm{~mm}$. bore. The tubes are marked at a level corresponding to $1.1 \mathrm{ml}$. fluid ; $0.1 \mathrm{ml}$. isotonic saline solution containing $0.004 \mathrm{mg}$. heparin is placed in each tube. For the test, blood is added up to the 1.1-ml. mark, the stopper is inserted, and the contents are mixed by inverting the tube several times. The end point is reached when the tube can be inverted without any fluid breaking away. To prevent contamination with tissue fluid, suction should be avoided during venipuncture until the needle has entered the vein ; and the tube should be filled from the middle of the syringe, the first and last blood to enter it being discarded.

The bore of the tube affects the result. In a narrow tube a surface clot develops before the entire contents are solid ; if the blood has a high sedimentation rate the sedimented corpuscles can be seen to flow on inversion for some time after the surface has solidified. In a wide tube the centre of the surface is the last part to clot and the tube cannot be inverted until the entire contents are solid. Observations with narrow and wide tubes filled from the same syringe show that the end point is always shorter, and often much shorter, in the narrow tube. The figures that follow refer to results obtained with narrow tubes. The test has many other technical defects. The end point is often very gradual and rarely sharp. Excessive shaking seems to retard coagulation. The time elapsing between venipuncture and mixing of the blood with heparin probably influences the result. Contamination of the blood with tissue fluid provides another possible source of error. Despite its defects, the test has differentiated several broad groups.

TABLE I

The Heparin-Retarded Coagulation Time in Controls, in ThromboPhlebitis, etc., in Cardiac Infarction, and in the Coronary ProDROMAL SYNDROME*

\begin{tabular}{|c|c|c|c|c|}
\hline & \multicolumn{4}{|c|}{ Heparin-retarded coagulation time in minutes } \\
\hline & $\begin{array}{l}\text { Accelerated } \\
5-9 \quad 10-16\end{array}$ & $\begin{array}{c}\text { Borderline } \\
17-19\end{array}$ & $\begin{array}{c}\text { Normal } \\
20-40\end{array}$ & $\begin{array}{l}\text { Prolonged } \\
\text { Over } 40\end{array}$ \\
\hline $\begin{array}{r}\text { Non-thrombotic conditions } \\
32\end{array}$ & 3 & 5 & 23 & 1 \\
\hline $\begin{array}{lr}\text { Thrombophlebitis, } & \text { em- } \\
\text { bolism, etc. } & 8\end{array}$ & 2 & 0 & 4 & 0 \\
\hline Cardiac infarction & 1126 & 11 & 35 & 5 \\
\hline $\begin{array}{l}\text { Coronary prodromal syn- } \\
\text { drome and cardiac } \\
\text { ischæmia }\end{array}$ & 12 & 4 & 36 & 1 \\
\hline
\end{tabular}

* No anticoagulant had been given prior to the test.

Rosenthal gives the normal clotting time as between 20 and 36 minutes. Personal experience in control cases suggests that with the narrower tubes the lower limit of normal is 17 or possibly 16 minutes (Table I). A figure of 16 minutes was obtained in two cases of gallstone colic ; a shorter clotting time of 13 minutes was only encountered once. 
Of 88 patients with cardiac infarction $48(55 \%)$ had an $H R C T$ of less than 20 minutes and 37 (42\%) of less than 17 minutes. Contrary to the report of Ogura et al. (1946) figures as low as 5 to 10 minutes have been obtained as early as the first day (Table II). There can be little doubt of the urgent necessity for anticoagulants in these cases. In some cases the $H R C T$ has been normal during the first day or two but has become accelerated later. Acceleration is frequent in the first three weeks and occasionally persists beyond the fourth week. In another group the HRCT has remained within the normal range throughout the attack. Finally, a few patients had a prolonged

TABLE II

The $H R C T$ at Different Times after the Onset of Cardiac Infarction.*

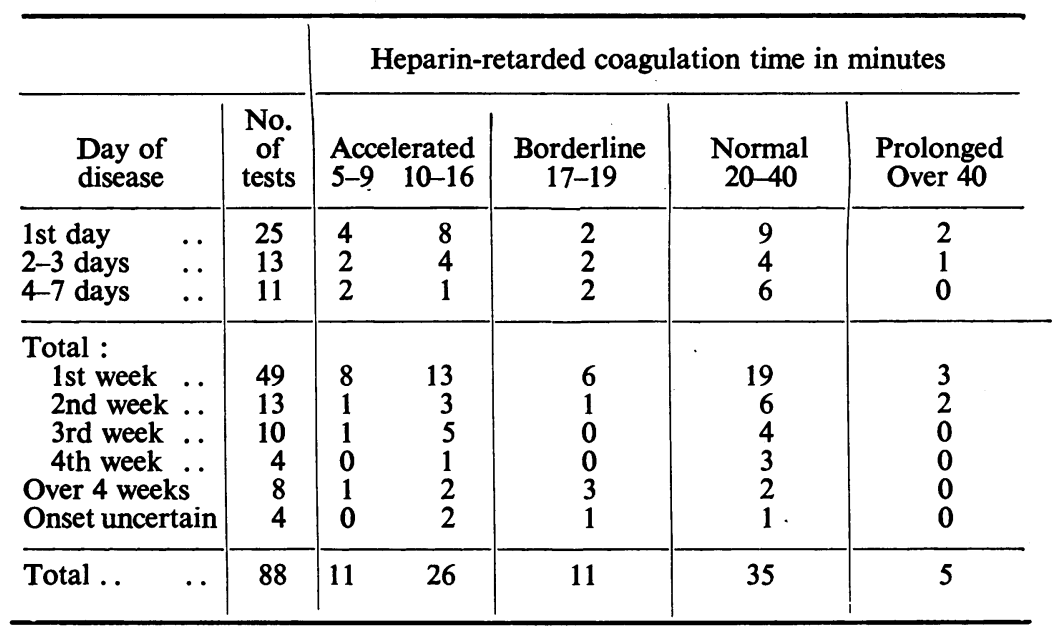

* No case had received anticoagulants prior to the test.

. HRCT which later fell to normal, and in one case became accelerated ; prolongation was only found during the first two weeks. Of 61 patients with cardiac ischæmia or coronary prodromal syndrome $24(39 \%)$ had an HRCT of under 20 minutes and $20(33 \%)$ of under 17 minutes (Table I).

The following serial observations are of interest. A man of 43, previously healthy, wakened with severe cardiac pain which lasted three hours; he spent two weeks in bed and was referred on the 19th day. He was then symptom-free but his cardiogram showed an anteroseptal infarct and his HRCT was 15 minutes. On the last day of a three-weeks' course of tromexan his HRCT was $\mathbf{4 0}$ minutes ; two days later it was 24 and on the following day 8 minutes. Two days after this he had a second attack of severe cardiac pain lasting 16 hours; when next seen a week after the second attack his $H R C T$ was 22 minutes. This case suggests that extension of thrombosis is likely when the $H R C T$ falls. It is possible that in consequence of thrombosis some constituent of blood is used up, leading to a rise in HRCT until the deficiency has been made good. The normal or prolonged HRCT sometimes found a day or two after the onset might be explained on this basis.

A man of 50 with thrombo-angeitis obliterans presented with a migrating thrombophlebitis of two months' duration; he had a fresh thrombotic lesion and his $H R C T$ was 23 minutes. On the last day of a three weeks' course of tromexan it was 32 minutes and the phlebitis seemed quiescent. The $H R C T$ was repeated three days later and thereafter at weekly intervals; the successive figures were $38,32,28$, and 23 minutes. At this stage a fresh lesion appeared.

\section{Results of Treatment in Cardiac Infarction using the HRCT as a Basis of Selection for ANTICOAGULANTS}

Twenty minutes was arbitrarily selected as the figure below which anticoagulants were given, above which they were withheld. If the $H R C T$ was normal on the first or second day, it was repeated daily until the third day and at intervals thereafter ; anticoagulants were given if and when the figure dropped below 20 minutes. Four patients originally placed in the " no anticoagulant 
group " were later transferred to the " anticoagulant group" because of acceleration that appeared between the third and twelfth days. The routine anticoagulant used was tromexan ; dosage was adjusted with the aim of keeping the prothrombin time at two and a half times the control figure. Heparin was given as well as tromexan for the first few days if early control seemed important on clinical grounds or because of an alarmingly short $H R C T$. More recently heparin had been given as a supplement to tromexan whenever the prothrombin time is less than twice the control value, whether at the start of treatment or later in the course. Prothrombin estimations were made daily. Heparin alone has not been used in cardiac infarction, but it was used alone in some patients with the coronary prodromal syndrome. Anticoagulant treatment was given for three weeks: the $H R C T$ was repeated on the last day of treatment and again two or three days later ; if accelerated at either test treatment was continued or resumed, the tests being repeated at the end of each subsequent week's treatment. In most cases the $H R C T$ was prolonged or high normal after three weeks and remained so ; several patients needed a fourth but only two needed a fifth week's treatment.

Table III shows the composition, complications, mortality, causes of death, and frequency of second attacks in 86 cases of coronary occlusion. All had cardiographic signs of cardiac infarction ; those in whom the clinical history suggested coronary occlusion but the cardiogram showed ischæmic changes only are not included in this table, but have been classified and are discussed as cardiac ischæmia.

The most striking findings are in the group of 38 patients from whom anticoagulants were withheld because of a normal or prolonged HRCT. Although this group includes 16 severe cases with shock and/or failure, a proportion almost identical with that found among the 48 patients

TABLE III

The Severity, Complications, Mortality, Causes of Death, and Incidence of Second ATtACKS IN 86 CASES OF CARDIAC INFARCTION

\begin{tabular}{|c|c|c|c|c|}
\hline & & & $\begin{array}{l}H R C T \text { under } 20 \text { minutes. } \\
\text { Anticoagulants given }\end{array}$ & $\begin{array}{l}\text { HRCT } 20 \text { minutes or more. } \\
\text { Anticoagulants withheld }\end{array}$ \\
\hline Total cases .. & .. & .. & 48 & 38 \\
\hline $\begin{array}{l}\text { Severity : } \\
\text { Shock or failure present } \\
\text { Shock and failure absen } \\
\end{array}$ & & $\ddot{x}$ & $\begin{array}{l}22=46 \% \\
26=54 \% \\
\end{array}$ & $\begin{array}{l}16=42 \% \\
22=58 \% \\
\end{array}$ \\
\hline $\begin{array}{l}\text { Complications : } \\
\text { Extension of infarct } \\
\text { Embolism } \quad . . \\
\end{array}$ & $\because$ & $\because$ & $\begin{array}{l}4=9 \% \\
5=10 \% \\
\end{array}$ & $\begin{array}{l}3=8 \% \\
2=5 \% \\
\end{array}$ \\
\hline $\begin{array}{l}\text { Death : } \\
\text { Within } 4 \text { weeks } \\
\text { Within } 6 \text { weeks }\end{array}$ & $\ddot{.}$ & $\because$ & $\begin{array}{l}6=13 \% \\
8=17 \%\end{array}$ & $\begin{array}{r}3=8 \% \\
5=13 \% \\
\end{array}$ \\
\hline $\begin{array}{l}\text { Cause of death : } \\
\text { Extension of infarct } \\
\text { Death from shock } \\
\text { Death from rupture } \\
\text { Pulmonary infarction } \\
\text { Cardiac failure. } . \\
\text { Ventricular fibrillation }\end{array}$ & $\begin{array}{l}\because \\
\cdots \\
. \\
.\end{array}$ & $\begin{array}{l}\cdots \\
\cdots \\
\cdots \\
\cdots\end{array}$ & $\begin{array}{l}\left.\begin{array}{l}2 \\
1 \\
1\end{array}\right\}=8 \% \\
\begin{array}{l}3=6 \% \\
1=2 \%\end{array}\end{array}$ & $\begin{array}{l}\left.\begin{array}{l}1 \\
0 \\
1\end{array}\right\}=5 \% \\
2=5 \% \\
1=3 \%\end{array}$ \\
\hline $\begin{array}{l}\text { Second attacks within } 6 \mathrm{~m} \\
\text { Survivors after } 6 \text { weeks } \\
\text { Second attacks occurred }\end{array}$ & $\begin{array}{l}\text { onths } \\
\text { d in }\end{array}$ & .. & $5=13 \%$ & $\begin{array}{c}33 \\
\quad 1=3 \% \\
+1 \text { sudden death }\end{array}$ \\
\hline
\end{tabular}

with accelerated $H R C T$, complications were less frequent, the mortality was lower, and second attacks within six months were infrequent. The mortality of 13 per cent in six weeks compares 
very favourably with that quoted by Tulloch and Gilchrist (1950) for anticoagulant-treated cases. One death resulted from extension of infarction. This was an early case in the series; he was seen ten hours after the onset of a severe attack and his HRCT was 32 minutes ; the importance of repeating the test on the second and third day was not realized. For a week he progressed satisfactorily but extension of infarction occurred on the 8th and he died on the 9th day. One death occurred from pulmonary infarction : this man was first seen on the $23 \mathrm{rd}$ day when his $H R C T$ was 35 minutes : the embolism took place two days later and he died on the 31st day. Two deaths were due to cardiac failure, on the 3rd and 13th days : one occurred suddenly in the 5th week from ventricular fibrillation.

Extension of infarction or embolism occurred in 5 cases including the two who died, an incidence of 13 per cent. The corresponding figure for cases with accelerated HRCT was 9 out of $48(19 \%)$ despite anticoagulant treatment. Finally, only one of the 33 survivors had a second attack within six months; whereas five of the 40 survivors in the accelerated group developed second attacks.

The mortality was higher in patients with accelerated $H R C T(17 \%$ in six weeks). Death from cardiac failure and sudden death from ventricular fibrillation occurred with equal frequency and together these caused a mortality of 8 per cent in each group. Thrombo-embolic deaths were more frequent in the accelerated group ( 8 as compared with $5 \%$ ). It is felt, however, that three deaths from extension of infarction might have been prevented. In each case tromexan failed to maintain a steady prothrombin time and the latter fell to a totally inadequate level at one stage ; each patient had cardiac pain with extension of infarction later that day; two became shocked and died within 24 to 48 hours ; the third ruptured her infarct four days later. Since these incidents the prothrombin time has been estimated daily ; supplementary heparin is now given as a routine whenever the figure is below twice the control value, and continued until this level is regained. A fall in prothrombin time has since occurred in several patients ; one had mild transient pain without extension of infarction ; in the others no ill effects followed. It is hoped to eliminate some deaths from extension of infarction by this technique and to reduce the mortality to the region of 10 per cent.

TABLE IV

DeAths AND Thrombo-embolic COMPlications

\begin{tabular}{|c|c|c|c|c|c|c|}
\hline & & & \multicolumn{2}{|c|}{$\begin{array}{l}\text { Severe attacks with shock } \\
\text { and/or failure }\end{array}$} & \multicolumn{2}{|c|}{$\begin{array}{l}\text { Attacks without shock or } \\
\text { failure }\end{array}$} \\
\hline & & & $\begin{array}{c}H R C T \\
\text { accelerated }\end{array}$ & $\begin{array}{l}H R C T \\
\text { normal }\end{array}$ & $\begin{array}{c}H R C T \\
\text { accelerated }\end{array}$ & $\begin{array}{l}H R C T \\
\text { normal }\end{array}$ \\
\hline Total cases & $\cdots$ & $\ldots$ & 22 & 16 & 26 & 22 \\
\hline \multicolumn{3}{|c|}{ Thrombo-embolic complications } & $7=32 \%$ & $3=19 \%$ & $2=8 \%$ & $2=9 \%$ \\
\hline $\begin{array}{l}\text { Deaths : } \\
\text { Within } 4 \text { weeks } \\
\text { Within } 6 \text { weeks } \\
\end{array}$ & $\cdots$ & $\begin{array}{l}\cdots \\
\cdots \\
\end{array}$ & $\begin{array}{l}5=23 \% \\
6=27 \%\end{array}$ & $\begin{array}{l}3=19 \% \\
4=25 \%\end{array}$ & $\begin{array}{l}1=4 \% \\
2=8 \%\end{array}$ & $\begin{array}{l}0 \\
1=5 \%\end{array}$ \\
\hline $\begin{array}{l}\text { Cause of death : } \\
\text { Thrombo-embolic } \\
\text { Cardiac failure }\end{array}$ & & 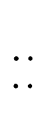 & $\begin{aligned} 2 & =9 \% \\
4^{*} & =18 \%\end{aligned}$ & $\begin{aligned} 1 & =6 \% \\
3^{*} & =19 \%\end{aligned}$ & $\begin{array}{l}2=8 \% \\
0\end{array}$ & $\begin{array}{l}1=5 \% \\
0\end{array}$ \\
\hline $\begin{array}{l}\text { Second attacks within } \\
\text { Survivors after } 6 \text { w } \\
\text { Second attack occu }\end{array}$ & $\begin{array}{l}\text { mont } \\
\text { ks }\end{array}$ & $\begin{array}{l}\text { as : } \\
\cdots \\
\cdots\end{array}$ & $\begin{array}{r}16 \\
2=13 \%\end{array}$ & $12=8 \%$ & $\stackrel{24}{3}=13 \%$ & $\begin{array}{l}21 \\
0 \text { (but } 1 \\
\text { sudden death) }\end{array}$ \\
\hline
\end{tabular}

* In each of these groups, one death was due to ventricular fibillation. 
The most important prognostic features are the presence or absence of shock or failure, with or soon after the onset ; but whether the attack be mild or severe the prognosis is further affected by the HRCT. Table IV gives the results separately for cases with and without shock or failure. Deaths from heart failure or ventricular fibrillation only occurred in patients with severe attacks ; but these caused death in almost one-fifth (18\%) of such patients irrespective of whether the HRCT was accelerated or normal. On the other hand death from extension of infarction or embolism was almost as frequent in mild as in severe attacks, but was more likely when the $H R C T$ was accelerated irrespective of the severity. Finally, a recurrence within six months occurred in one of every eight survivors whose $H R C T$ was accelerated whether the original attack was mild or severe ; only one recurrence took place among twelve survivors from major attacks with a normal $H R C T$ and there were no second attacks among twenty-one survivors from mild attacks with normal $H R C T$.

The frequency of second attacks in the accelerated group despite anticoagulant treatment is disappointing but probably not without significance for prophylaxis. They may develop soon after completion of treatment. Thus a patient was seen on the 26th day after a mild posterior infarct ; his $H R C T$ was 10 minutes. It was 18 minutes after three, and 45 minutes after four weeks' tromexan ; four days later it was 35 minutes. A fortnight after this he was readmitted in a second attack with anterolateral extension of the infarct ; his HRCT had dropped to 20 minutes. He had a second four weeks' course of tromexan ; three weeks after discharge he was admitted to another hospital in a third attack, details of which are not available. It seems advisable to estimate the $H R C T$ at weekly intervals after a course of treatment until a steady level is maintained ; a prophylactic course should be considered if the HRCT approaches the danger level. Second attacks have been rather more frequent recently : of 326 survivors during 1928-50, $18(6 \%)$ had a recurrence within 6 months ; of 73 survivors in the present series $6(8 \%)$ had a second attack ; five of them had received anticoagulants because of an accelerated $H R C T$.

\section{The HRCT as a Selective Test for Prophylactic Treatment}

The test was applied in patients with recent abrupt onset of effort angina, in those with paroxysmal cardiac pain at rest, and in those with prolonged cardiac pain at rest whose 12-lead cardiogram failed to show the QRS changes of infarction. In some the cardiogram was normal, in some it showed ischæmic changes, and in some there were other abnormalities such as left ventricular stress. Anticoagulants were given if the $H R C T$ was below 20 minutes. The numbers so far are too small to justify positive claims but the results are encouraging. Of 50 analogous cases in private practice during 1946-50, 10 developed infarction within six weeks, 27 escaped infarction, and 13 remain untraced. Of 51 cases in 1951-52, 3 developed infarction within six weeks; 27 with accelerated $H R C T$ were anticoagulant-treated and provided two infarcts ; 24 with normal $H R C T$ received no anticoagulants and yielded one infarct.

\section{SUMMARY}

A modification of Rosenthal's " heparin-retarded coagulation time" was used to select cases of cardiac infarction, cardiac ischæmia, and coronary prodromal syndrome for anticoagulant therapy. The technique of the test requires improvement, but it has differentiated cases with acceleration of coagulation time from those with normal or prolonged values. Each group contained an almost identical proportion of severe cases with shock and/or failure.

Cardiac infarction with accelerated $H R C T$ had a mortality of 17 per cent despite anticoagulants. Cardiac infarction with a normal or prolonged $H R C T$ had a mortality of 13 per cent although anticoagulants were withheld. Deaths from cardiac failure and ventricular fibrillation were equally frequent in the two groups ; thrombo-embolic deaths account for the difference. Second attacks within six months were much more frequent in survivors who had an accelerated $H R C T$ and had received anticoagulants. 
The $H R C T$ is of help in determining the duration of anticoagulant therapy and may indicate the need for prophylactic courses after recovery. Heparin should be given as well as tromexan until the prothrombin time exceeds twice the control value and whenever it falls below this critical level.

Cases of cardiac infarction in which the $H R C T$ remains normal may justifiably be treated without anticoagulants ; facilities thus released may be used for prophylactic treatment in prodromal or convalescent cases selected on the basis of the test. The results of prophylactic treatment are regarded as encouraging.

It is a pleasure to express my thanks to Dr. J. Craig for estimating prothrombin times, supervising tromexan and heparin dosage, and carrying out the HRCT during and after treatment ; to Drs. J. J. McCall, A. K. Bain, D. D. G. Simpson, and R. I. Alexander, Registrar and Residents respectively, for numerous $H R C T$ estimations ; and to many general practitioners whose co-operation has made possible a complete follow up of these cases.

\section{REFERENCES}

Mounsey, P. (1951). Brit. Heart J., 13, 215.

Ogura, J. H., Fetter, H. R., Blankenhorn, M. A., and Glueck, H. T. (1946). J. clin. Invest., $25,586$.

Papp, C., and Smith, K. S. (1951, a). Brit. med. J., 1, 1471.

- - $(1951$, b). Brit. Heart J. 13, 17.

$-,-(1951$, c). Brit. Heart J., 13, 467.

Rosenthal, R. L. (1949). J. lab. clin. Med., 34, 1321.

Tulloch, J. A., and Gilchrist, A. R. (1950). Brit. med. J., 2, 965.

Waugh, T. R., and Ruddick, D. W. (1944). Canad. med. Ass. J., 50, 547. 